\title{
Treatment adherence among sputum smear- positive pulmonary tuberculosis patients in mountainous areas in China
}

Song Yao ${ }^{1 *}$, Wen-Hui Huang ${ }^{2}$, Susan van den Hof ${ }^{3,4}$, Shu-Min Yang ${ }^{5}$, Xiao-Lin Wang ${ }^{6}$, Wei Chen ${ }^{7}$, Xue-Hui Fang ${ }^{1}$ and Hai-Feng Pan $^{8}$

\begin{abstract}
Background: We carried out an investigation in five provinces in China to assess treatment adherence and identify factors associated with insufficient treatment adherence in tuberculosis (TB) patients in mountainous, rural areas of China.

Methods: In each of the five provinces, all counties with $>80 \%$ mountainous area were stratified into three groups according to their gross domestic product. In each stratum, one county was randomly sampled. Study subjects were sampled from all smear positive TB cases registered in 2007 in the target counties. TB patients, village doctors, county doctors and directors of the TB prevention and control institutes were interviewed. Insufficient medication adherence was defined as taking less than 90\% of anti-TB drug doses prescribed. Insufficient re-examination adherence was defined as having less than the recommended three sputum smear examinations during the treatment course.
\end{abstract}

Results: A minority of patients took drugs under direct observation: on average $29 \%$ during the intensive phase of treatment. In total, 524 TB patients were included, of whom 49 (9.4\%) took less than $90 \%$ of all doses prescribed and $92(17.6 \%)$ did not have all sputum smear examinations, with substantial variations between the provinces. In multivariable analysis, no direct observation of treatment during the intensive phase and the presence of adverse events were associated both with insufficient medication adherence and insufficient re-examination adherence. Overall, $79 \%$ of patients were adherent both to treatment and re-examinations.

Conclusions: In these remote and poor areas of China, the TB control program is not fully functioning according to the guidelines. The majority of patients are not treated under direct observation, while direct observation by health care staff was associated with better adherence, both to drug therapy and re-examinations. Insufficient adherence increases the risk of unsuccessful treatment outcomes and development of drug resistance. Measures should be taken urgently in these areas to strengthen implementation of the international Stop TB strategy.

\section{Background}

Adherence, or compliance, refers to the extent patients correctly follow medical advice [1]. Adherence refers both to taking drugs according to prescription and to adherence to other recommendations such as attending medical check-ups. Within the international tuberculosis (TB) control strategy [2], direct observation of treatment (DOT) was introduced to improve treatment outcomes

\footnotetext{
* Correspondence: ys506506@yahoo.com.cn

${ }^{1}$ Anhui Provincial TB Research Institute; Hefei, China

Full list of author information is available at the end of the article
}

[3]. Non-adherence increases the risk of prolonged infectiousness, development of drug resistance, relapse of $\mathrm{TB}$, and death [3-10]. Barriers to adherence include poor literacy of patients on health in general and lack of comprehension of benefits of treatment and risks of prematurely stopping treatment specifically, occurrence of side effects, and costs [11].

China ranks second on the list of countries with the highest number of yearly, incident TB cases [12]. In 2009, an estimated 1.3 million individuals in China got TB. A recent study in Jiangsu province in China found
C Biomed Central 
that $12 \%$ of patients did not take at least $10 \%$ of their prescribed doses of anti-TB treatment [13]. Another study in Hebei province however observed that $46 \%$ missed at least $10 \%$ of the doses [14]. Several other studies in China also indicated low treatment adherence among sputum smear-positive pulmonary tuberculosis patients [15-18]. However, only one province or one city had been investigated in these previous studies. Moreover, studies in mountainous areas of China are very limited. In rural, mountainous areas in China, limited access to transportation, the large service area of health clinics and village doctors, and poverty may complicate access to health care for diagnosis and treatment of TB even more than in other rural areas [19]. We carried out an investigation in five provinces in China to assess treatment adherence and identify factors associated with insufficient treatment adherence in tuberculosis patients in mountainous, rural areas of China. These results may be used to develop targeted measures to improve patient treatment adherence and hereby improve cure and reduce development of drug resistance and recurrence of $\mathrm{TB}$.

\section{Methods}

\section{Study population and sampling}

This cross-sectional comparative study was conducted in counties with at least $80 \%$ of the population living in mountainous areas. Five provinces with a significant proportion of mountainous area in their province participated in the study: Anhui, Ningxia, Gansu, Jiangxi and Guizhou. Situated inland astride the Yangzi (Yangtse or Changjiang) River, Anhui is a rich agricultural land on the fringes of the North China plain. Situated near the geographical central northern edge, Ningxia Province belongs more naturally to the North-Western group of provinces. Gansu Province is the north-western corridor into China, bounded by inhospitable, mountainous Qinghai to the south-west and the Gobi desert to the north-east, it forms the natural route for the overland silk routes into the heartland of China. Jiangxi is a fairly mountainous inland province with a long history. The town of Jingdezhen is famous for its blue and white porcelain. Guizhou is not one thing or another, it's near the border with Vietnam but not on the border and in the mountains but not the high mountains, it has a somewhat transitional climate too, between the tropical and the continental types.

Of all counties in these provinces, 17 (16\%), 8 (36\%), 46 (53\%), 42 (42\%), 75 (85\%) respectively, had at least $80 \%$ of the population living in mountainous areas. Per province, these mountainous counties were stratified in three strata (tertiles) according to the provincial per capita gross domestic product (GDP). Per stratum, one county was randomly selected so that in total 15 counties, three from each of five provinces, were included in the sample.

We calculated that with a sample size of 500 , assuming a rate of exposed to unexposed of $1: 2$ and $25 \%$ chance of disease among the unexposed, we would be able to demonstrate an odds ratio of minimally 2 with alpha $=0.05$ and beta $=0.10$. Therefore, we aimed to interview 35 smear-positive pulmonary TB patients per county.

We randomly sampled smear positive cases from all smear positive cases registered in 2007 in the target mountainous counties. Sampling was performed in batches until 35 cases per county had been included. In one county in Ningxia province, 34 cases were included. A sample of 556 individuals was necessary to include these 524 (94\%) patients. The main reason for non-participation was individuals having migrated out of the county for work.

\section{Data collection}

We examined which patient related factors (e.g. age and sex), healthcare provider related factors (e.g. treatment supervision), and socio-economic factors (e.g. local GDP) were associated with poor adherence to anti-TB drugs and poor adherence to smear examinations during the treatment period.

A total of 524 TB patients were interviewed at the county level TB institutes by county level TB staff, using structured questionnaires on treatment adherence and factors associated with low treatment adherence. Each item of the questionnaire was carefully explained to the study subjects, all the questionnaire was administered by trained interviewers. A preliminary investigation was carried out before formal study.

In order to assess which reasons $\mathrm{TB}$ physicians thought to be associated with insufficient adherence, structured interviews were held with the director of each county TB dispensary, with doctors at the county level TB dispensary, and with doctors at the township and village level. TB dispensary doctors prescribe treatment and examine patients during follow-up medical examinations while township and village doctors monitor treatment.

The same protocol was used in each province. In each province, county level investigators were trained by the provincial level investigators during a one day workshop before data collection. Data collection took place between October 2008 and January 2009, so that the whole 2007 cohort had finished treatment.

In the standardized thrice-weekly treatment regimen new patients should take drugs 90 times and smearpositive retreatment patients 120 times. If there are one or more sputum smear-positive results during treatment, then treatment will be extended. The total 
number of times the patients should have taken drugs were taken from the patient medication record card. A patient was defined to have good adherence to treatment if the proportion of actual doses taken of those prescribed was at least $90 \%$.

According to the national TB program (NTP) guideline, both new and retreatment patients should have three sputum smear examinations during the treatment course (at 2, 5, 6 after the start of treatment for new patients and 2, 5, 8 months for retreatment patients). A patient was defined to have good adherence to smear re-examinations if he or she had at least three smear reexaminations.

After completion of questionnaire investigation by the county level staff, provincial research staff re-interviewed $10 \%$ of included patients ( 4 per county). In all counties, re-interviews gave similar results.

\section{Data analysis}

Data were double entered using EpiData version 3.1, and all statistic analyses were performed by Statistical Package for Social Sciences (SPSS), version 10.0. Chi-square tests were used to identify associations between patient and treatment characteristics and treatment adherence. Separate analyses were performed for risk factors for insufficient adherence to taking of anti-TB drugs, and for insufficient adherence to sputum smear re-examinations. To assess independent risk factors for non-adherence, variables with a P-value $<0.2$ in univariate analysis were included in multivariable logistic regression models. By backward selection based on the -2 log likelihood ratio, the final model was selected. The level of significance was set at $P<0.05$.

\section{Ethical considerations}

The investigation was carried out after written informed consent of study participants. The study was approved by the Ethics Committee of the national TB control association.

\section{Results}

\section{Study population characteristics}

In the study population consisting of $524 \mathrm{~TB}$ patients, the average age was 47.7 (standard deviation 17.5) years, 364 (69.5\%) were males, and 427 (81.5\%) were farmer. Overall, $142(27.1 \%)$ of the patients had no formal education while a further $172(32.8 \%)$ had no education beyond primary school. The distribution of demographic characteristics of the TB patients and characteristics of their treatment are shown in more detail in Table 1. Between provinces, striking differences were observed in the proportion of patients without formal education, the proportion of patients that were aware of the free policy for TB diagnosis and treatment, the distances from patients' homes to village clinics, the proportion of patients receiving DOT during the intensive phase, and the proportion of patients receiving DOT during the continuation phase (P-values $<0.001)$. The proportion

Table 1 Description of TB patients and their treatment per province

\begin{tabular}{|c|c|c|c|c|c|c|}
\hline & $\begin{array}{l}\text { Anhui }(n= \\
\text { 105) }\end{array}$ & $\begin{array}{l}\text { Ningxia }(n= \\
104)\end{array}$ & $\begin{array}{l}\text { Jiangxi }(\mathrm{n}= \\
105)\end{array}$ & $\begin{array}{l}\text { Guizhou ( } \mathrm{n}= \\
\text { 105) }\end{array}$ & $\begin{array}{l}\text { Ganshu }(\mathrm{n}= \\
\text { 105) }\end{array}$ & $\begin{array}{l}\text { Total }(n= \\
524)\end{array}$ \\
\hline participation (\%) & 95.2 & 94.2 & 93.3 & 92.4 & 94.3 & 94.2 \\
\hline male (\%) & 77.1 & 59.6 & 78.1 & 69.5 & 62.9 & 69.5 \\
\hline Mean age (SD) in years & $51.5 \pm 16.4$ & $46.6 \pm 17.7$ & $44.7 \pm 13.9$ & $46.4 \pm 18.8$ & $49.1 \pm 19.5$ & $47.7 \pm 17.5$ \\
\hline previously treated patients (\%) & 2.9 & 15.4 & 7.6 & 10.5 & 9.5 & 9.2 \\
\hline without formal education (\%) & 17.1 & 54.8 & 8.6 & 16.2 & 39.0 & 27.1 \\
\hline $\begin{array}{l}\text { aware of free policy for TB diagnosis and } \\
\text { treatment (\%) }\end{array}$ & 49.5 & 70.2 & 74.3 & 44.8 & 89.5 & 65.6 \\
\hline \multicolumn{7}{|l|}{ Distance from home to village clinics (\%) } \\
\hline$<1 \mathrm{~km}$ & 42.9 & 37.5 & 29.5 & 5.7 & 53.3 & 33.8 \\
\hline $1-2 \mathrm{~km}$ & 40.0 & 18.3 & 47.6 & 55.2 & 29.5 & 38.2 \\
\hline$>2 \mathrm{~km}$ & 17.1 & 44.2 & 22.9 & 39.1 & 17.2 & 28.1 \\
\hline \multicolumn{7}{|l|}{$\begin{array}{l}\text { Distance from home to diagnostic and re- } \\
\text { examination center }\end{array}$} \\
\hline$<20 \mathrm{~km}$ & 36.2 & 30.8 & 43.8 & 21.9 & 39 & 34.4 \\
\hline $20-40 \mathrm{~km}$ & 27.6 & 34.6 & 40 & 35.2 & 36.2 & 34.7 \\
\hline$>40 \mathrm{~km}$ & 36.2 & 34.6 & 16.2 & 42.9 & 24.8 & 30.9 \\
\hline with DOT during intensive phase (\%) & 26.7 & 43.3 & 31.4 & 9.5 & 35.2 & 29.2 \\
\hline with DOT during continuation phase (\%) & 24.8 & 37.5 & 30.5 & 8.6 & 28.6 & 26.0 \\
\hline
\end{tabular}

$\mathrm{SD}=$ standard deviation; $\mathrm{DOT}$ = direct observation of treatment 
of patients without formal education ranged between $8.6 \%$ and $54.8 \%$, and the proportion of patients that were aware of the free policy for TB between $44.8 \%$ and $89.5 \%$. On average, $21.8 \%$ lived more than 2 kilometers from the village clinic and $30.9 \%$ lived more than 40 kilometers from the re-examination center. Despite differences, the proportion of patients receiving DOT was low in all provinces: it ranged between $9.5 \%$ and $43.3 \%$ during the intensive phase and between $8.6 \%$ and $37.5 \%$ in the continuation phase.

\section{Adherence to taking of anti-TB drugs}

On average, forty-nine $(9.4 \%)$ of patients reported having taken less than $90 \%$ of the drug doses prescribed. This percentage ranged from $0 \%$ in Ningxia province to $10.5 \%$ in Anhui province $(\mathrm{p}=0.02)$ (Table 2). Characteristics associated with poor adherence in univariate analysis were province, not having a formal education, no supervision visits by (village) doctor during treatment, adverse effects during treatment, no DOT during the intensive phase, no DOT during the continuation phase, and DOT conducted outside the patient's home or no DOT conducted as compared to home-based DOT (Table 2). In multivariate analysis, independent risk factors for poor adherence were experiencing adverse effects during treatment, no DOT during the intensive phase and no home-based DOT. Observation of treatment by volunteers tended also to decrease the chance of non-adherence $(\mathrm{p}=$ $0.06)$.

Table 2 Tuberculosis patient and treatment characteristics associated with taking less than $90 \%$ of prescribed doses of anti-TB treatment

\begin{tabular}{|c|c|c|c|c|c|c|c|c|}
\hline & & & $\begin{array}{l}\text { drug } \\
\text { ence }\end{array}$ & Unive & rariate & & Adju & sted \\
\hline & $\mathrm{N}$ & $\mathbf{n}$ & $\%$ & OR & $95 \% \mathrm{Cl}$ & $p$-value & OR & $95 \% \mathrm{Cl}$ \\
\hline Province & & & & & & 0.02 & & \\
\hline Anhui & 105 & 11 & $10.5 \%$ & 1.00 & & & & \\
\hline Ningxia & 104 & 0 & $0 \%$ & - & - & & & \\
\hline Jiangxi & 105 & 9 & $8.6 \%$ & 0.80 & $0.32-2.02$ & & & \\
\hline Guizhou & 105 & 22 & $21.0 \%$ & 2.27 & $1.04-4.95$ & & & \\
\hline Ganshu & 105 & 7 & $6.7 \%$ & 0.61 & $0.23-1.64$ & & & \\
\hline Education level & & & & & & 0.04 & & \\
\hline No formal education & 142 & 7 & $4.9 \%$ & 1.00 & & & & \\
\hline At least primary school & 382 & 42 & $11.0 \%$ & 2.38 & $1.04-5.43$ & & & \\
\hline TB patient category & & & & & & 0.20 & & \\
\hline New & 476 & 42 & $8.8 \%$ & 1.00 & & & & \\
\hline Retreatment & 48 & 7 & $14.6 \%$ & 1.76 & $0.75-4.18$ & & & \\
\hline Adverse effects during treatment & & & & & & $<0.01$ & & \\
\hline Yes & 312 & 41 & $13.1 \%$ & 1.00 & & & 1.00 & \\
\hline No & 212 & 8 & $3.8 \%$ & 0.26 & $0.12-0.57$ & & 0.30 & $0.17-0.53$ \\
\hline DOT during the intensive phase & & & & & & $<0.01$ & & \\
\hline no DOT & 241 & 33 & $13.7 \%$ & 1.00 & & & 1.00 & \\
\hline DOT by village doctors & 153 & 5 & $3.3 \%$ & 0.21 & $0.08-0.56$ & & 0.28 & $0.09-0.82$ \\
\hline DOT by volunteers & 130 & 11 & $8.5 \%$ & 0.58 & $0.28-1.20$ & & 0.44 & 0.19-1.03 \\
\hline DOT during continuation phase & & & & & & 0.02 & & \\
\hline no DOT & 253 & 31 & $12.3 \%$ & 1.00 & & & & \\
\hline DOT by village doctors & 136 & 4 & $2.9 \%$ & 0.22 & $0.08-0.63$ & & & \\
\hline DOT by volunteers & 135 & 14 & $10.4 \%$ & 0.83 & $0.42-1.62$ & & & \\
\hline Supervision visits by (village) doctor during treatment & & & & & & $<0.001$ & & \\
\hline Yes & 462 & 35 & $7.6 \%$ & 1.00 & & & & \\
\hline No & 62 & 14 & $22.6 \%$ & 3.56 & $1.79-7.08$ & & & \\
\hline Time DOT observer spends with the patient during observation of treatment & & & & & & 0.003 & & \\
\hline DOT at home, $\leq 10$ minutes & 181 & 10 & $5.5 \%$ & 1.00 & & & 1.00 & \\
\hline DOT at home, $>10$ minutes & 198 & 15 & $7.6 \%$ & 1.40 & $0.61-3.20$ & & 2.10 & $0.82-5.42$ \\
\hline DOT outside home or no DOT & 145 & 24 & $16.6 \%$ & 3.39 & $1.57-7.35$ & & 3.49 & $1.42-8.62$ \\
\hline
\end{tabular}




\section{Adherence to sputum smear re-examinations}

On average, ninety-two (17.6\%) patients did not have all three re-examinations. This proportion ranged from 9.5\% in Anhui province to $49.5 \%$ in Guizhou province $(\mathrm{p}<0.001)$ (Table 3$)$.

In univariate analysis, factors associated with incomplete adherence to re-examinations were province, male gender, adverse effects during treatment, return trip costs to the diagnostic and re-examination center $>20$ $\mathrm{RMB}$, no supervision visits by (village) doctor during treatment, and not having a DOT observer during treatment at homeland (Table 3). Independent risk factors associated with incomplete adherence to re-examinations were province, experiencing adverse effects, and not having a DOT observer at home.

\section{Structured interviews with TB doctors}

A total of 85 village doctors, 32 county doctors and 15 directors of county-level tuberculosis prevention and control institutions from five provinces were interviewed. TB doctors from the township/village and county level attributed insufficient treatment adherence to: adverse effects (50 doctors, 43\%), difficulties associated with traffic and distances in mountainous areas (26 doctors, 22\%), insufficient awareness of TB and insufficient attention to TB symptoms (16 doctors, 14\%), migrant work (12 doctors, 10\%), financial difficulties associated with TB disease and treatment (11 doctors, $10 \%$ ) and the long duration of anti-TB treatment (9 doctors, $8 \%$ ). The main difficulties village doctors encountered in TB work were a lack of government funding for TB control tasks (28 doctors, 32.9\%), inconvenient traffic and distances in mountain areas (19 doctors, 22.4\%), low treatment adherence of patients (10 doctors, $11.8 \%$ ) low education level of patients (6 doctors, $7.1 \%$ ), and high workload (5 doctors, 5.9\%). The main difficulties county doctors encountered in their work were workplace related: lack of government funding ( $\mathrm{n}=10,31 \%)$, outdated equipment ( $\mathrm{n}=7,21.9 \%)$, and insufficient human resources $(n=6,18.8 \%)$. In addition, low treatment adherence was mentioned relatively often as a difficulty encountered in their work ( $n=7,21.9 \%)$.

Of the 15 directors of the county-level TB prevention and control institutions interviewed, 5 considered government funding for TB control to be insufficient to meet operational needs.

\section{Discussion}

In our study population from five provinces, on average 9.4\% (range: $0 \%-21.0 \%$ ) of TB patients missed more than $10 \%$ of the number of prescribed doses and on average $17.6 \%$ (range: $6.7 \%-49.5 \%$ ) of them did not go to the CDC for all smear re-examinations. The proportion of non-adherent patients was lowest in Ningxia province and highest in Guizhou province. Overall, 79\% of patients complied sufficiently both to treatment and reexaminations.

DOT aims to improve adherence in order to improve treatment outcomes and prevent creation of drug resistance. Our results show that DOT is not implemented well in the five mountainous provinces of China included in our study. During the intensive phase, on average $71.2 \%$ of $\mathrm{TB}$ patients were not treated under direct observation and this proportion ranged from $56.7 \%$ in Ningxia province to $90.5 \%$ in Guizhou province. Our results is similar to the results of Sun et al [15], they reported the majority of TB patients in rural areas do not receive DOT from village doctors and rarely get support, such as visits as required, from the CTBDs or township health providers in Shandong, China. Another study in Chongqing by $\mathrm{Hu}$ et al also found DOT is not well implemented, only less than $5 \%$ of TB patients (17/401) were observed by health staff [18].

The patients included from Guizhou province least often got treatment under direct observation and had significantly lower adherence to both medication and sputum re-examinations. Lack of treatment under direct observation and experiencing adverse events during treatment were the only independent risk factors which negatively influenced adherence both to treatment and to re-examinations in our study. Re-examinations during treatment are important to monitor the response to the therapy and allow identification and management of adverse events, which in turn may help to prevent nonadherence to therapy including default. A recent study from China showed that many patients were not aware of the importance of sputum re-examinations [20]. It has been observed before that adverse events during treatment increase the risk of non-adherence to therapy [13,20-25]. Driver [26] studied determinants for treatment interruption and found that the lack of TB disease and treatment related knowledge were important reasons for patients discontinuing treatment. Indeed, health education has shown to improve treatment adherence [24]. In addition, pscychosocial support from family, friends and professionals can improve patient adherence [24-28].

The doctors in fact mentioned that low treatment adherence was a problem they encountered in their work. A high workload and the remoteness of the areas they work in may prevent them to take appropriate actions to supervise patients and improve adherence. Strengthening and/or increasing human resources and improving work conditions may help improve the TB control program. Because of the economic difficulties and traffic problems patients experience in these remote and poor areas of China, providing additional incentives 
Table 3 Tuberculosis patient and treatment characteristics associated with incomplete attendance of re-examinations during treatment

\begin{tabular}{|c|c|c|c|c|c|c|c|c|}
\hline & & \multicolumn{2}{|c|}{$\begin{array}{l}\text { Incomplete } \\
\text { re-examination }\end{array}$} & \multicolumn{2}{|c|}{ Univariate } & \multicolumn{3}{|c|}{ Adjusted } \\
\hline & $\mathrm{n}$ & $\mathrm{n}$ & (\%) & OR & $(95 \% \mathrm{Cl})$ & p-value & OR & $(95 \% \mathrm{Cl})$ \\
\hline Province & & & & & & $<0.001$ & & \\
\hline Anhui & 105 & 10 & $9.5 \%$ & 1.00 & & & 1.00 & \\
\hline Ningxia & 104 & 7 & $6.7 \%$ & 0.69 & $0.25-1.88$ & & 0.83 & $0.29-2.3$ \\
\hline Jiangxi & 105 & 12 & $11.4 \%$ & 1.23 & $0.51-2.98$ & & 1.30 & $0.53-3.2$ \\
\hline Guizhou & 105 & 52 & $49.5 \%$ & 9.32 & $\begin{array}{l}4.38- \\
19.84\end{array}$ & & 11.64 & $5.1-26.7$ \\
\hline Ganshu & 105 & 11 & $10.5 \%$ & 1.11 & $0.45-2.74$ & & 2.24 & $0.84-5.9$ \\
\hline TB patient category & & & & & & 0.16 & & \\
\hline New & 476 & 80 & $16.8 \%$ & 1.00 & & & & \\
\hline Retreatment & 48 & 12 & $25 \%$ & 1.65 & $0.82-3.31$ & & & \\
\hline Gender & & & & & & 0.05 & & \\
\hline male & 364 & 72 & $19.8 \%$ & 1.00 & & & & \\
\hline female & 160 & 20 & $12.5 \%$ & 0.58 & 0.34-0.99 & & & \\
\hline Age (years) & & & & & & 0.12 & & \\
\hline$\leq 45$ & 238 & 36 & $15.1 \%$ & 1.00 & & & & \\
\hline $45-65$ & 193 & 33 & $17.1 \%$ & 1.16 & $0.69-1.94$ & & & \\
\hline$>65$ & 93 & 23 & $24.7 \%$ & 1.84 & $1.02-3.33$ & & & \\
\hline Awareness of free diagnosis and treatment policy & & & & & & 0.19 & & \\
\hline Yes & 344 & 55 & $16.0 \%$ & 1.00 & & & & \\
\hline No & 180 & 37 & $20.6 \%$ & 1.36 & $0.86-2.16$ & & & \\
\hline Patients had heard about tuberculosis before seeking care & & & & & & 0.10 & & \\
\hline Yes & 297 & 45 & $15.2 \%$ & 1.00 & & & & \\
\hline No & 227 & 47 & $20.7 \%$ & 1.46 & $0.93-2.30$ & & & \\
\hline Distance from home to village clinics & & & & & & 0.11 & & \\
\hline$<1 \mathrm{~km}$ & 177 & 23 & $13 \%$ & 1.00 & & & & \\
\hline $1-2 \mathrm{~km}$ & 200 & 37 & $18.5 \%$ & 1.52 & $0.86-2.67$ & & & \\
\hline$>2 \mathrm{~km}$ & 147 & 32 & $21.8 \%$ & 1.86 & $1.04-3.35$ & & & \\
\hline Return trip costs to diagnostic and re-examination center & & & & & & 0.008 & & \\
\hline$\leq 20 \mathrm{RMB}$ & 373 & 55 & $14.7 \%$ & 1.00 & & & & \\
\hline$>20 \mathrm{RMB}$ & 151 & 37 & $24.5 \%$ & 1.88 & $1.18-3.00$ & & & \\
\hline Adverse effects during treatment & & & & & & $<0.001$ & & \\
\hline Yes & 312 & 71 & $22.8 \%$ & 1.00 & & & 1.00 & \\
\hline No & 212 & 21 & $9.9 \%$ & 0.37 & $0.22-0.63$ & & 0.33 & $0.18-0.59$ \\
\hline DOT during the intensive phase & & & & & & 0.12 & & \\
\hline no DOT & 241 & 51 & $21.2 \%$ & 1.00 & & & & \\
\hline DOT by village or town doctors & 153 & 24 & $15.7 \%$ & 0.69 & $0.41-1.18$ & & & \\
\hline DOT by volunteers & 130 & 17 & $13.1 \%$ & 0.56 & $0.31-1.02$ & & & \\
\hline DOT observer during ambulatory treatment & & & & & & 0.006 & & \\
\hline No DOT observer & 138 & 44 & $31.90 \%$ & 1.00 & & & 1.00 & \\
\hline Family member, volunteer or other & 230 & 31 & $13.50 \%$ & 0.33 & $0.20-0.56$ & & 0.61 & $0.29-1.3$ \\
\hline village doctor or township doctor & 156 & 17 & $10.90 \%$ & 0.26 & $0.14-0.49$ & & 0.33 & $0.18-0.63$ \\
\hline Supervision visits by (village) doctor during treatment & & & & & & $<0.001$ & & \\
\hline Yes & 462 & 69 & $14.9 \%$ & 1.00 & & & & \\
\hline$\overline{\mathrm{No}}$ & 62 & 23 & $37.1 \%$ & 3.36 & $1.89-5.97$ & & & \\
\hline
\end{tabular}


Table 3 Tuberculosis patient and treatment characteristics associated with incomplete attendance of re-examinations during treatment (Continued)

\begin{tabular}{|c|c|c|c|c|c|}
\hline $\begin{array}{l}\text { time DOT observer spends with the patient during observation of } \\
\text { treatment }\end{array}$ & & & & & 0.006 \\
\hline DOT at home, $\leq 10$ minutes & 181 & 31 & $17.1 \%$ & 1.00 & \\
\hline DOT outside home & 100 & 21 & $21.0 \%$ & 1.35 & $0.76-2.63$ \\
\hline no DOT & 45 & 16 & $35.6 \%$ & 2.24 & $1.45-3.72$ \\
\hline
\end{tabular}

to support patients like reimbursement of costs related to TB treatment like for transport may also help improve adherence to both medical check-ups and drug treatment.

There are three main limitations to this study. Firstly, $6 \%$ of sampled patients did not participate. It is not clear to what extent they are different from participants and thus to what extent this may have caused bias. However, as the non-participation rate was low, we do not expect that it biased our results considerably. Secondly, as patients were interviewed after treatment, they may not have remembered all details correctly. This may have made results more imprecise. It also is possible that patients were reluctant to admit to missing doses of drugs, despite the explanation that the answers would have no consequences for the patients whatsoever. Thirdly, we were not able to include a qualitative study component with in depth interviews in order to obtain insight into reasons for non-DOT and noncompliance.

\section{Conclusions}

In these mountainous areas of China, the TB control program is not fully functioning according to the guidelines. The majority of patients are not treated under direct observation, while direct observation by health care staff was associated with better adherence, both to drug therapy and re-examinations. Measures should be taken urgently in these areas to strengthen implementation of the Stop TB strategy.

\section{Acknowledgements}

This research project received funding through the China Global Fund TB Program (CHN-405-G04-T). We are deeply indebted to the patients and doctors who have participated in this study. We also thank all staff who supported this research.

\footnotetext{
Author details

${ }^{1}$ Anhui Provincial TB Research Institute; Hefei, China. ${ }^{2}$ Jiangxi Provincial Center for Disease Control and Prevention; Nanchang, China. ${ }^{3} \mathrm{KNCV}$ Tuberculosis Foundation, The Hague, the Netherlands. ${ }^{4}$ Center for Infection and Immunity Amsterdam (CINIMA), University of Amsterdam, Amsterdam, The Netherlands. ${ }^{5}$ Gansu Provincial Center for Disease Control and Prevention; Lanzhou, China. ${ }^{6}$ Ningxia Provincial Center for Disease Control and Prevention; Yinchuan, China. ${ }^{7}$ Guizhou Provincial Center for Disease Control and Prevention; Guiyang, China. ${ }^{8}$ Department of Epidemiology and Biostatistics, School of Public Health, Anhui Medical University, Hefei, China.
}

\section{Authors' contributions}

SY, WH, SH, SMY, XW, WC and XF all helped to design the study, coordinate data collection, assist in data-analysis, and drafting of the manuscript. HP was involved in coordination and critical reviewing of the manuscript. All authors read and approved the final manuscript.

\section{Competing interests}

The authors declare that they have no competing interests.

Received: 26 January 2011 Accepted: 16 December 2011

Published: 16 December 2011

\section{References}

1. Zhang Y: Patient adherence and drug use. Chinese Journal of Pharmacoepidemiology 2001, 10:206-208, [in Chinese].

2. World Health Organization: The Stop TB Strategy World Health Organization, Geneva, Switzerland; 2006, WHO/HTM/TB/2006.368.

3. Volmink J, Garner P: Directly observed therapy for treating tuberculosis. Cochrane Database Syst Rev 2007, 4:CD003343.

4. Mitchison DA: How drug resistance emerges as a result of poor adherence during short course chemotherapy for tuberculosis. Int J Tuberc Lung Dis 1998, 2:10-15.

5. Zellweger JP, Coulon P: Outcome of patients treated for tuberculosis in Vaud County, Switzerland. Int J Tuberc Lung Dis 1998, 2:372-377.

6. Burman WJ, Cohn DL, Rietmeijer CA, Judson FN, Sbarbaro JA, Reves RR: Nonadherence with directly observed therapy for tuberculosis. Epidemiology and effect on the outcome of treatment. Chest 1997, 111:1168-1173.

7. Hoskyns W: Paediatric tuberculosis. Postgrad Med J 2003, 79:272.

8. Jiang W, Liu Y: Analysis of factors that affect the adherence of tuberculosis chemotherapy. China and Foreign Medical Journal 2004, 2:26-28, [in Chinese].

9. Palwatwicha A: Tuberculosis in Thailand. Respirology 2001, 6:65-70.

10. Johansson E, Diwan VK, Huong ND, Ahlberg BM: Staff and patient attributes to tuberculosis and adherence with treatment: an exploratory study in district in Vietnam. Tuber Lung Dis 1996, 77:178-183.

11. Munro SA, Lewin SA, Smith HJ, Engel ME, Fretheim A, Volmink J: Patient adherence to tuberculosis treatment: $A$ systematic review of qualitative research. PloS Med 2007, 4:e238.

12. World Health Organization: WHO Report 2010. Global Tuberculosis Control Epidemiology, Strategy, Financing Geneva, Switzerland: World Health Organization; 2010, WHO/HTM/TB/2010.7.

13. Xu W, Lu W, Zhou Y, Zhu L, Shen H, Wang J: Adherence to antituberculosis treatment among pulmonary tuberculosis patients: a qualitative and quantitative study. BMC Health Services Research 2009, 9:1-8.

14. Zhao $L$, Xie X, Shen Y: Research Analysis on Medication Adherences of Tuberculosis Patients. China Pharmacy 2005, 16:1311, [in Chinese].

15. Sun Q, Meng Q, Yip W, Yin X, Li H: DOT in rural China: experience from a case study in Shandong Province, China. Int J Tuberc Lung Dis 2008, 12:625-30

16. Long Q, Li Y, Wang Y, Yue Y, Tang C, Tang S, Squire SB, Tolhurst R: Barriers to accessing TB diagnosis for rural-to-urban migrants with chronic cough in Chongqing, China: a mixed methods study. BMC Health Serv Res 2008, 8:202.

17. Wei X, Liang X, Liu F, Walley JD, Dong B: Decentralising tuberculosis services from county tuberculosis dispensaries to township hospitals in China: an intervention study. Int J Tuberc Lung Dis 2008, 5:538-47. 
18. Hu D, Liu X, Chen J, Wang Y, Wang T, Zeng W, Smith H, Garner P: Direct observation and adherence to tuberculosis treatment in Chongqing, China: a descriptive study. Health Policy Plan 2008, 1:43-55.

19. Liu X, Thomson R, Gong Y, Zhao F, Squire SB, Tolhurst R, Zhao X, Yan F, Tang S: How affordable are tuberculosis diagnosis and treatment in rural China? An analysis from community and tuberculosis patient perspectives. Trop Med Int Health 2007, 12:1464-1471.

20. Ai X, Men K, Guo L, Zhang T, Zhao Y, Sun X, Zhang H, He G, van der Werf MJ, van den Hof S: Factors associated with low cure rate of tuberculosis in remote poor areas of Shaanxi Province, China: a case control study. BMC Public Health 2010, 10:112

21. Widjanarko B, Gompelman M, Dijkers M, van der Werf MJ: Factors that influence treatment adherence of tuberculosis patients living in Java, Indonesia. Patient Prefer Adherence 2009, 3:231-238.

22. Shen J, Lei T, Wang Z: Study on the relevant factors of adherence that affect the regular treatment for pulmonary TB. The Journal Of The Chinese Antituberculosis Association 2007, 29:133-135, [in Chinese].

23. Adherence World Health Organization: Adherence to long-term therapies World Health Organization, Geneva, Switzerland; 2003, WHO/MNC/03.01.

24. Morsky D, Malotte C, Choi P: A patient education programme to improve adherence rates with anti-tuberculosis drug regimens. Health Educ $Q$ 1999, 17:253-267.

25. Addington WW: Patient adherence, the most serious remaining problem in the control of tuberculosis in the United States. Chest 1979, 76:741-743.

26. Driver CR, Matus SP, Bayuga S, Winters Al, Munsiff SS: Factors associated with tuberculosis treatment interruption in New York City. J Public Health Manag Pract 2005, 11:361-368.

27. Sabaté E: Adherence to long-term therapies Geneva: World Health Organization; 2003.

28. Kaona FA, Tuba M, Siziya S, Sikaona L: An assessment of factors contributing to treatment adherence and knowledge of TB transmission among patients on TB treatment. BMC Public Health 2004, 4:68.

\section{Pre-publication history}

The pre-publication history for this paper can be accessed here: http://www.biomedcentral.com/1472-6963/11/341/prepub

doi:10.1186/1472-6963-11-341

Cite this article as: Yao et al:: Treatment adherence among sputum smear-positive pulmonary tuberculosis patients in mountainous areas in China. BMC Health Services Research 2011 11:341.

\section{Submit your next manuscript to BioMed Central and take full advantage of:}

- Convenient online submission

- Thorough peer review

- No space constraints or color figure charges

- Immediate publication on acceptance

- Inclusion in PubMed, CAS, Scopus and Google Scholar

- Research which is freely available for redistribution

Submit your manuscript at www.biomedcentral.com/submit
Biomed Central 